\title{
THE
}

\section{Piezoresistive Properties of ITO Strain Sensors Prepared with Controlled Nanoporosity}

Otto J. Gregory

University of Rhode Island, ogregory@uri.edu

Tao You

Follow this and additional works at: https://digitalcommons.uri.edu/che_facpubs

Part of the Chemical Engineering Commons

Terms of Use

All rights reserved under copyright.

\section{Citation/Publisher Attribution}

Gregory, O. J., \& Tao You, T. (2004). Piezoresistive Properties of ITO Strain Sensors Prepared with Controlled Nanoporosity. Journal of the Electrochemical Society, 15(8), H198-H203. doi: 10.1149/ 1.1767839

Available at: http://dx.doi.org/10.1149/1.1767839

This Article is brought to you for free and open access by the Chemical Engineering at DigitalCommons@URI. It has been accepted for inclusion in Chemical Engineering Faculty Publications by an authorized administrator of DigitalCommons@URI.For more information, please contact digitalcommons-group@uri.edu. 


\title{
Piezoresistive Properties of ITO Strain Sensors Prepared
with Controlled Nanoporosity
}

\author{
Otto J. Gregory ${ }^{\mathrm{z}}$ and Tao You
}

Sensors and Surface Technology Partnership, Department of Chemical Engineering, University of Rhode Island, Kingston, Rhode Island 02881, USA

\begin{abstract}
A ceramic strain gage based on reactively sputtered indium-tinoxide (ITO) thin films is being developed to monitor the structural integrity of components employed in aerospace propulsion systems operating at temperatures in excess of $1500^{\circ} \mathrm{C}$. The hightemperature stability and piezoresistive properties depend to a large extent on the thickness of the active ITO strain elements comprising these ceramic strain gages. Scanning electron microscopy of the thick ITO sensors revealed a partially sintered microstructure consisting of a contiguous network of submicrometer ITO particles with well-defined necks and isolated nanoporosity. It appeared that densification of the ITO particles was retarded during high-temperature exposure with nitrogen playing a key role in stabilizing the nanoporosity. Based on these preliminary results, ITO strain sensors were also prepared by reactive sputtering in various nitrogen/oxygen/argon partial pressures to incorporate more nitrogen into the films. Under these conditions, sintering and densification of the ITO particles containing these nitrogen-rich grain boundaries was retarded and a contiguous network of nanosized ITO particles was established. The influence of nitrogen in the sputtered and annealed ITO films on the microstructure and the high-temperature piezoresistive properties was investigated, and the results are presented in this paper. (C) 2004 The Electrochemical Society. [DOI: 10.1149/1.1767839] All rights reserved.
\end{abstract}

Manuscript received August 7, 2003. Available electronically June 25, 2004.

As the operating temperature of gas turbine engines is increased and new materials are developed to meet these new challenges, there is a need to assess the structural behavior of components in these harsh environments, so that structural models can be validated and newly developed materials can be monitored during actual engine operation. Thin film sensors are ideally suited to make measurements of operational turbine conditions since they have negligible mass and thus, minimal impact on vibration patterns. They are nonintrusive in that the gage thickness is considerably less than the gas-phase boundary layer thickness and thus the gas flow path through the engine will not be adversely affected by these sensors. Not only are these sensors ideally suited for in situ strain measurement where high gas velocities are encountered, but these ceramic strain gages have excellent adhesion and similar thermal expansion coefficients to most oxides used for electrical isolation. ${ }^{1-8}$ In addition, ceramic sensors are refractory, nonintrusive, and robust enough to withstand the high g loading associated with rotating components. For these reasons, ceramic strain gages based on alloys of indiumtin oxide (ITO) were developed to monitor both the static and dynamic strain of components employed in advanced propulsion systems and active control surfaces. ${ }^{9-11}$

The active ITO strain elements in these ceramic sensors are oxidation resistant and do not undergo any phase changes when thermally cycled between room temperature and $1500^{\circ} \mathrm{C} .{ }^{12}$ In addition, the piezoresistive response of ITO-based strain sensors is one to two orders of magnitude greater than those observed in metals and the ITO sensors have superior electrical and chemical stability relative to metals in these harsh environments. ${ }^{13-19}$ Consequently, improved signal-to-noise ratios are possible with these ceramic strain gages due to the inherently large piezoresistive responses. In operational turbine measurements, the enhanced sensitivity and responsiveness of the ceramic sensors are particularly important since the signals are usually processed via slip ring technology or telemetry systems, which are susceptible to excessive noise. A measure of the responsiveness or strain sensitivity of these ceramic sensors is given by the gage factor $(G)$, which is defined according to Eq. 1

$$
G=\frac{\Delta R}{R_{\text {ref }}} \cdot \frac{1}{\varepsilon}
$$

where $R_{\text {ref }}$ is the resistance at a reference temperature $T_{\text {ref }}, \Delta R$ is the change in resistance, and $\varepsilon$ is the applied microstrain. However, also critical in these aerospace applications is the electrical

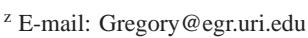

and chemical stability of the sensors, which must operate at temperatures that can exceed $1500^{\circ} \mathrm{C}$. The drift rate $(D R)$ of these electrical strain gages is a measure of the stability and is defined according to Eq. 2

$$
D R=\frac{\Delta R}{R_{\text {ref }}} \cdot \frac{1}{\Delta t_{\text {time }}}
$$

The influence of sensor thickness on the piezoresistive response and stability of ITO sensors was investigated. By systematically varying thickness of ITO strain gages prepared by rf sputtering and annealing in nitrogen at $800^{\circ} \mathrm{C}$, a correlation between microstructure and high-temperature properties was established. Very thick ITO active strain elements exhibited a partially sintered microstructure containing nanosized ITO particles. This microstructure was largely responsible for the excellent high-temperature properties exhibited by these materials.

ITO strain gages with controlled nanoprosity were prepared by subjecting relatively thick ITO films to a postdeposition anneal at $800^{\circ} \mathrm{C}$ in nitrogen and exposure to high temperature, or by reactive sputtering in various nitrogen/oxygen/argon partial pressures and exposure to high temperature. The relationship between microstructure and the high-temperature stability of ITO strain sensors prepared by these two techniques was investigated. Scanning electron microscopy (SEM) indicated that although the microstructures of the nitrogen-sputtered films were similar in appearance to those produced by a postdeposition anneal in nitrogen, the average pore size and particle size were an order of magnitude smaller for those sensors prepared by sputtering in nitrogen overpressures. It appears that nitrogen was metastably retained in the individual ITO grains during sputtering and diffused out of the bulk grains at elevated temperature, eventually becoming trapped at grain boundaries and triple junctions. Under these conditions, sintering and densification of the ITO particles containing these nitrogen-rich grain boundaries was retarded and a contiguous network of nanosized ITO particles was established. The controlled microstructures in these sensors are possible due to the decomposition of ITO in nitrogenbearing atmospheres which can occur at temperatures as low as $1100^{\circ} \mathrm{C} .^{20,21} \mathrm{By}$ controlling the partial pressure of nitrogen in the porosity during processing, a balance between the rate of decomposition and the sintering rate could be achieved so that the desired microstructure would persist for prolonged periods at elevated temperatures. Static strain testing of the nitrogen-sputtered ITO sensors indicated that a similarly stable and responsive strain gage could be readily reproduced. Microstructural evidence to support the 


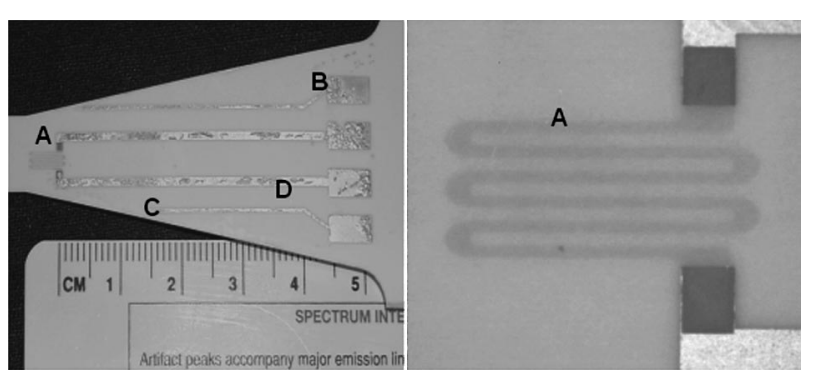

Figure 1. Photograph of an aluminum oxide constant strain beam with deposited ITO thin film strain sensor and associated platinum thin film leads. (A) ITO strain sensor, (B) platinum bond pads, (C) aluminum oxide constant strain beam, and (D) platinum thin film leads are shown in detail.

hypothesis that partially sintered microstructures with controlled nanoporosity could be stabilized to very high temperatures is presented herein, as well as the results of static strain tests at temperatures up to $1600^{\circ} \mathrm{C}$.

\section{Experimental}

High purity aluminum oxide constant strain beams were used for all high-temperature static strain tests, since they provide excellent electrical isolation at high temperature. These constant strain beams were laser-cut into the desired shape from rectangular plates of 99.9\% pure alumina (Coors Ceramics). Prior to deposition of ITO thin films onto the alumina constant beams, approximately $5 \mu \mathrm{m}$ of high purity alumina was sputtered onto these surfaces and heattreated at $1000^{\circ} \mathrm{C}$ in air. The sputtered alumina layer provided enhanced adhesion to the substrate while limiting impurity diffusion from the substrate to the deposited ITO thin films. All substrates were cleaned by rinsing in acetone, methanol, and distilled water, followed by a nitrogen blow dry. Photolithography techniques were used in conjunction with lift-off to fabricate all thin-film strain gages. Etching tends to cause hot corrosion of the sensors at high temperature due to residual chlorides on the surfaces of the coatings and thus was avoided whenever possible. All lithography processes employed a polyimide-based photoresist in conjunction with a modified lift-off process to transfer the desired sensor pattern. A polyimide photoresist (LOR10B obtained from Microchem, Inc.) was applied to the constant strain beam by spin coating at a spin speed of $2000 \mathrm{rpm}$ and subsequently baked at $150^{\circ} \mathrm{C}$. High bake temperatures are required with this photoresist due to its high glass transition temperature. An imaging resist (Shipley SC1827) was applied directly onto the LOR10B surface by spin-casting, followed by soft baking at $120^{\circ} \mathrm{C}$ for $4 \mathrm{~min}$. A photomask containing the desired artwork was placed over the resist-coat substrate and exposed to UV light. After exposure and development, the unwanted photoresist remaining on the alumina substrate was cleaned in an oxygen plasma to remove all organics. The ITO films were deposited by rf reactive sputtering using an MRC 822 sputtering system. Sputtered ITO thicknesses were varied between 2.5 and $15 \mu \mathrm{m}$. A high density ITO target $(12.7 \mathrm{~cm}$ in diameter) with a nominal composition of 90 wt $\% \mathrm{In}_{2} \mathrm{O}_{3}$ and $10 \mathrm{wt} \% \mathrm{SnO}_{2}$ was used for all ITO depositions and a high purity ( $99.9999 \%)$ platinum target $(10.7 \mathrm{~cm}$ in diameter) was used for all platinum depositions. The sputtering chamber was evacuated to a background pressure $<1 \times 10^{-6}$ Torr prior to sputtering and semiconductor grade argon, oxygen, and nitrogen were leaked into the chamber to establish a total gas pressure of 9 mTorr. The oxygen, argon, and nitrogen partial pressures were maintained in the deposition chamber using MKS mass flow controllers, and $\mathrm{rf}$ power density of $2.4 \mathrm{~W} / \mathrm{cm}^{2}$ was used for all ITO sputtering runs. Platinum films (3-4 $\mu \mathrm{m}$ thick) were used to form ohmic contacts to the active ITO strain elements and thin-film leads to make electrical connection to the data acquisition system. A photograph of a typical ceramic strain gage complete with the active ITO strain elements and the platinum leads and bond pads is shown in Fig. 1.

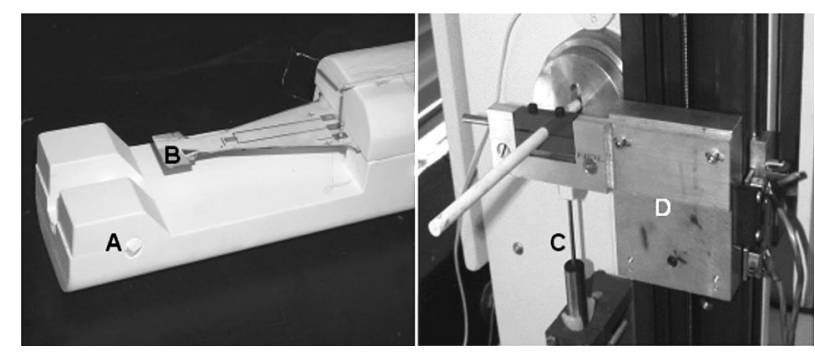

Figure 2. Photograph of (A) the high temperature, cantilever bend fixture with (B) aluminum oxide constant strain beam clamped into position. (A) The zirconium phosphate cantilever bend fixture with the external controls are shown in detail, including $(\mathrm{C})$ the LVDT-linear variable differential transducer, limit switches, (D) stepper motor, and cantilever rod.

A Deltech tube furnace with a 7 in. hot zone was used for hightemperature strain experiments. The furnace was ramped at $3^{\circ} \mathrm{C} / \mathrm{min}$ to the desired temperature in $50^{\circ} \mathrm{C}$ increments and held for at least 1 $\mathrm{h}$ to establish thermal equilibrium. Strain was induced by means of a cantilever-bending fixture fabricated from a machinable zirconium phosphate ceramic. A linear variable differential transducer (LVDT) was attached to a solid alumina rod and connected to the alumina constant strain beam to transfer strain to the active sensor element (Fig. 2). The corresponding resistance changes were monitored with a 6 digit multimeter (Hewlett-Packard 34401A) and a programmable constant current source (Keithley 224). A Hewlett-Packard multimeter and Keithley constant current source were interfaced to an I/O board and an IBM 488 GPIB card for continuous data acquisition using Labwindows software. A type $\mathrm{S}$ thermocouple connected to a second multimeter was used to measure the temperature inside the Deltech furnace.

\section{Results and Discussion}

A number of ceramic strain gages having different ITO thicknesses comprising the active strain elements were deposited on high purity aluminum oxide constant strain beams and tested under static strain conditions at temperatures up to $1600^{\circ} \mathrm{C}$. The piezoresistive response of a typical ceramic strain gage at $1157^{\circ} \mathrm{C}$ is shown in Fig. 3. This ceramic sensor had a $2.5 \mu \mathrm{m}$ thick active ITO strain element and exhibited a relatively small piezoresistive response and a relatively large drift rate, i.e., a gage factor of 3.52 and a drift rate of $0.016 \% / \mathrm{h}$ at $1157^{\circ} \mathrm{C}$. It should be noted here that the piezoresistive response is out of phase with the excitation signal and the positive slope of the piezoresistive response is an indication of signal drift. These results were very different from those obtained when thick ITO films were employed as the active strain elements in these ceramic strain gages. When relatively thin ITO films were used, the piezoresistive response was comparable to metals at lower temperatures $\left(1157^{\circ} \mathrm{C}\right)$ as shown in Fig. 3a, but became unstable at temperatures above $1225^{\circ} \mathrm{C}$, as shown in Fig. $3 \mathrm{~b}$. It should be noted here that the waveform associated with the piezoresistive response had severely degraded and the baseline resistance has increased by several orders of magnitude, which typically occurs just prior to failure. In contrast to this behavior, ITO sensors prepared with $5 \mu \mathrm{m}$ thick active strain elements and $8 \mu \mathrm{m}$ thick active strain elements were very stable and responsive even at higher temperatures. For example, ITO sensors prepared with $5 \mu \mathrm{m}$ thick active strain elements exhibited a gage factor of 6.8 and drift rate of $0.08 \% / \mathrm{h}$ at $1438^{\circ} \mathrm{C}$ (Fig. 4) and sensors prepared with $8 \mu \mathrm{m}$ thick active strain elements exhibited a gage factor of 20.9 and a drift rate of $0.00001 \% / \mathrm{h}$ at $1441^{\circ} \mathrm{C}$ (Fig. 5a). The latter strain sensor did not become unstable until temperatures approached $1481^{\circ} \mathrm{C}$ (Fig. 5b). Based on the results of the high-temperature static strain tests, we have determined that the piezoresistive response and electrical stability of the ceramic strain gages was very dependent on the thickness of ITO films comprising the active strain elements. A summary of the results from the 

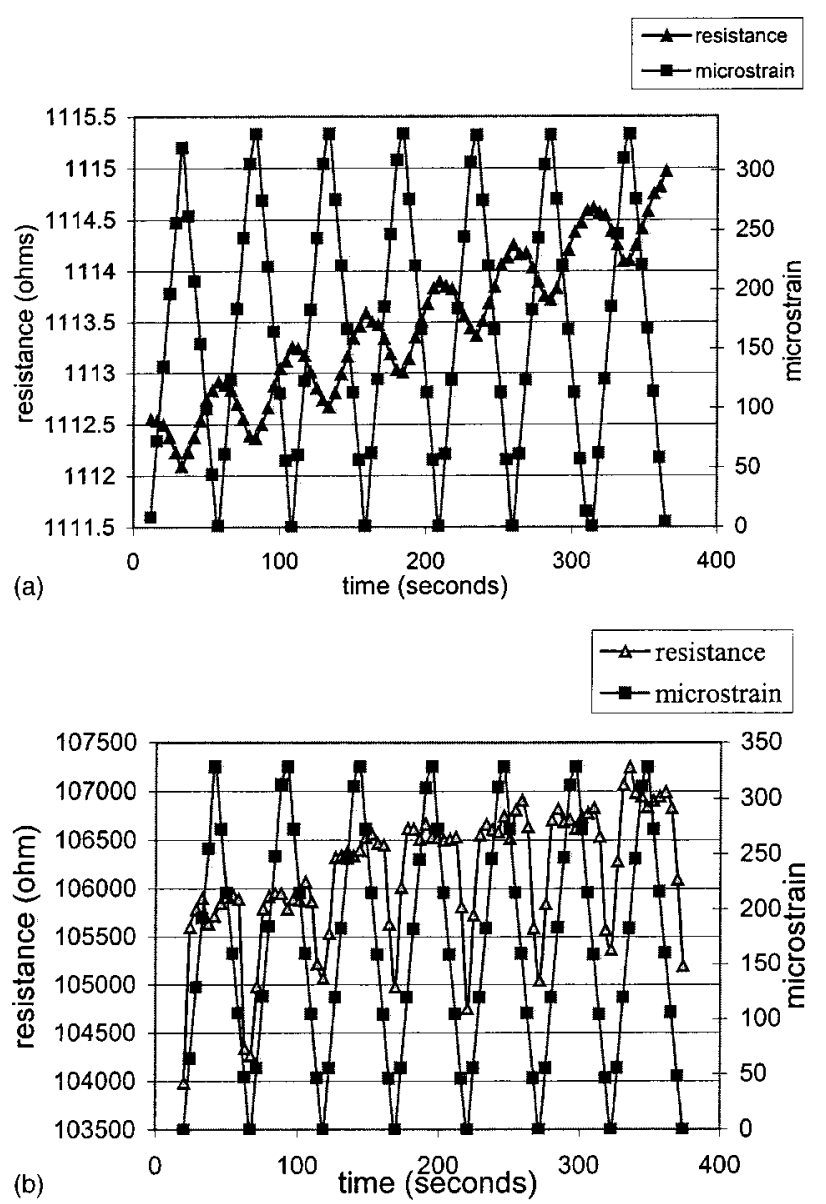

Figure 3. (a) Piezoresistive response of a $2.5 \mu \mathrm{m}$ thick ITO strain sensor at $1157^{\circ} \mathrm{C}$. The strain sensor was subjected to a postdeposition heat-treatment in nitrogen and had a gage factor of 3.52 and a drift rate of $0.016 \% / \mathrm{h}$. Note the piezoresistive response is out of phase with the excitation signal. The positive slope associated with the waveform is an indication of signal drift. (b) Piezoresistive response of a $2.5 \mu \mathrm{m}$ thick ITO strain sensor at $1225^{\circ} \mathrm{C}$, just prior to failure. The strain sensor was subjected to a postdeposition heat-treatment in nitrogen. Note that the waveform associated with the piezoresistive response had severely degraded and the baseline resistance had increased by several orders of magnitude.

static strain tests are presented in Table I, including the thickness dependence on stability, the temperature at which sensor failure occurred, and the piezoresistive response.

When ceramic strain gages were prepared with very thick ITO films $(10-15 \mu \mathrm{m})$ as the active strain elements, both the high temperature stability and gage factor were significantly improved relative to ITO films prepared in the 2.5-8 $\mu \mathrm{m}$ thickness range. Figure 6 shows the piezoresistive response of a ceramic strain gage employing a $10 \mu \mathrm{m}$ thick film of ITO as active strain element. This sensor was extremely stable and responsive with a gage factor of 131 and a drift rate of $0.00001 \% / \mathrm{h}$ at $1528^{\circ} \mathrm{C}$. Similarly, the piezoresistive response of a ceramic strain gage employing a $15 \mu \mathrm{m}$ thick ITO film as the active strain element is shown in Fig. 7. Here, an extremely stable and responsive strain gage was achieved with this $15 \mu \mathrm{m}$ thick ITO sensor at $1446^{\circ} \mathrm{C}$. An average gage factor and drift rate of 24.9 and $0.00001 \% / \mathrm{h}$, respectively, were established over the course of several hours of strain testing. The high-temperature piezoresistive properties of these thick ITO films are significantly better than those observed for ITO sensors prepared with very thin active strain elements. The only difference between the 10 and the $15 \mu \mathrm{m}$ thick strain ITO strain gages was the considerably lower baseline resistance associated with the $15 \mu \mathrm{m}$ thick strain gages. This marked improvement in the piezoresistive response and stabil-

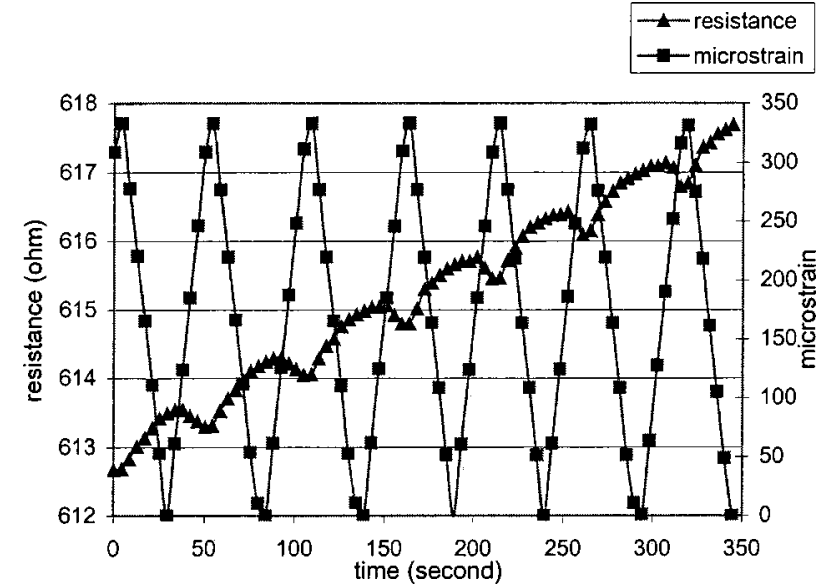

Figure 4. Piezoresistive response of a $5 \mu \mathrm{m}$ thick ITO strain sensor at $1438^{\circ} \mathrm{C}$, just prior to failure. The strain sensor was subjected to a postdeposition heat-treatment in nitrogen and had a gage factor of 6.8 and a drift rate of $0.08 \% / \mathrm{h}$. Note positive slope of the waveform which is an indication of signal drift. Also note the degradation of the waveform that typically occurs just before failure.

ity associated with these very thick ITO gages leads us to believe that significant changes in the microstructure of the ITO films had occurred either as a result of processing the films or postdeposition heat-treatment.

Initially, the extremely stable and responsive ITO strain sensors were prepared by sputtering very thick ITO films in oxygen:argon atmospheres and subsequently annealing them in nitrogen at $800^{\circ} \mathrm{C}$. As suspected, a marked change in microstructure had occurred in the thick ITO strain gages relative to the thin ITO strain gages prepared in this manner. The ITO sensors were examined prior to and after strain testing by SEM. An SEM micrograph of a thick ITO sensor $(10 \mu \mathrm{m})$ subjected to a postdeposition heat-treatment in nitrogen (Fig. 8) showed that a porous network with considerable surface roughness had developed after high-temperature exposure. Examination at higher magnifications of the same surface indicated that the microstructure consisted of an aggregate of partially sintered particles, i.e., a contiguous network of nanosized ITO particles with well-defined necks and isolated nanopores. A fractured surface of a thick ITO sensor subjected to a postdeposition heat-treatment in nitrogen and heated to $1530^{\circ} \mathrm{C}$ is shown in Fig. 9. This crosssectional view of the sensor at low magnification reveal that the interior regions of the thick ITO film contain a large number of isolated nanopores while the surface layers consisted of a higher density, coarser grain material where appreciable sintering and densification had occurred. Similar microstructures had been reported during the rapid heating and sintering of nanocrystalline ITO ceramic particles. ${ }^{22}$ There, Kim et al. ${ }^{22}$ reported that once a densified outer region had formed, the interior regions of the powder compact were not able to densify because the outer layer constrains the densification geometrically. In our case, the densified or sintered outer layer of the ITO film prevented oxygen from diffusion into the bulk film, which further stabilized the ITO at elevated temperature. When the as-deposited and nitrogen-annealed ITO film (Fig. 10) was compared to the same film after high-temperature exposure (Fig. 8), it was evident that the nanoporous microstructure had developed after high-temperature exposure, i.e., the microstructure was developed after the temperature exceeded $1500^{\circ} \mathrm{C}$. This finding was consistent with that of Kim et al. ${ }^{22}$ who observed sluggish densification behavior in nanocrystalline ITO particles when sintered at temperatures approaching $1600^{\circ} \mathrm{C}$.

In an attempt to metastably retain more nitrogen into the ITO films, a series of ITO films were sputtered in nitrogen overpressures using different argon/oxygen/nitrogen partial pressures. Not only did this process permit us to incorporate more nitrogen into the film but 


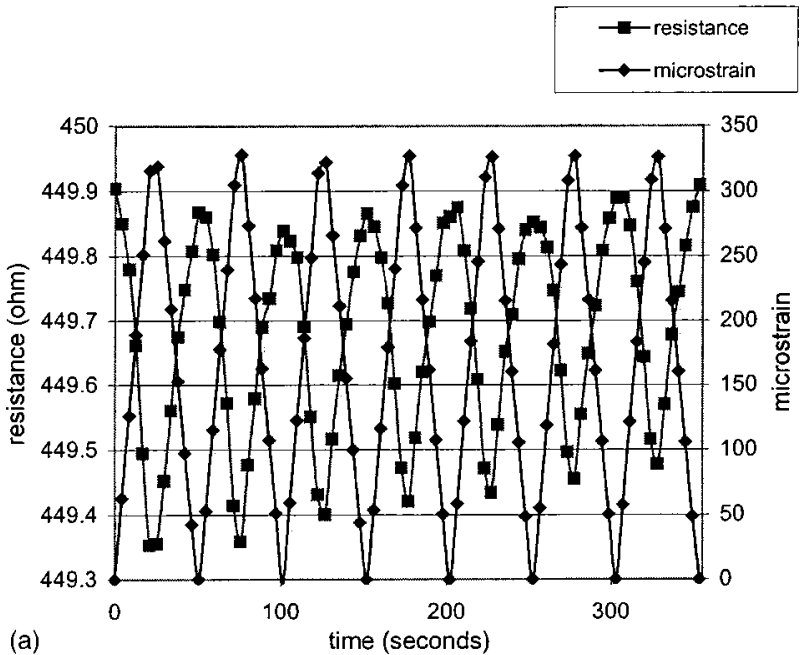

(a)

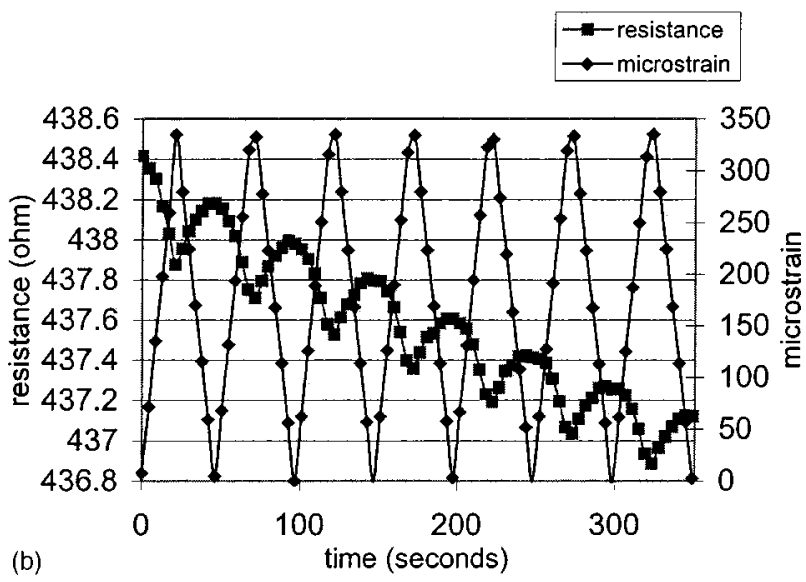

Figure 5. (a) Piezoresistive response of an $8 \mu \mathrm{m}$ thick ITO strain sensor at $1441^{\circ} \mathrm{C}$. The strain sensor was subjected to a postdeposition heat-treatment in nitrogen and had a gage factor of 20.9 and a drift rate of $0.00001 \% / \mathrm{h}$. Note the excellent stability of the signal as evidenced by the nearly flat response of the waveform. (b) Piezoresistive response of an $8 \mu \mathrm{m}$ thick ITO strain sensor at $1481{ }^{\circ} \mathrm{C}$, just prior to failure. The strain sensor was subjected to a postdeposition heat treatment in nitrogen and had a gage factor of 13.79 and a drift rate of $0.028 \% / \mathrm{hr}$. Note the negative slope of the piezoresistive response.

also allowed us to produce similar microstructures in more controllable manner. The SEM micrograph in Fig. 11 confirmed our hypothesis that by sputtering in a nitrogen-rich atmosphere we could produce a similar microstructure, i.e., a microstructure similar to those associated with the thick ITO films subjected to a postdeposition heat-treatment (Fig. 8). However, even though the same partially sintered microstructure with extensive neck formation was ob-

\begin{tabular}{|c|c|c|c|c|}
\hline $\begin{array}{l}\text { ITO } \\
\text { thickness }\end{array}$ & $\begin{array}{c}\text { Temperature } \\
{ }^{\circ} \mathrm{C}\end{array}$ & Gage factor & $\begin{array}{c}\text { Drift rate } \\
(\% / \mathrm{h})\end{array}$ & $\begin{array}{c}\text { Failure } \\
\text { Temperature } \\
{ }^{\circ} \mathrm{C}\end{array}$ \\
\hline 2.5 & 1157 & 3.52 & 0.0160 & 1157 \\
\hline 5 & 1438 & 6.8 & 0.0800 & 1438 \\
\hline 8 & 1441 & 20.9 & 0.0001 & 1481 \\
\hline 8 & 1481 & 13.79 & 0.0280 & 1481 \\
\hline 10 & 1528 & 131 & 0.00001 & 1544 \\
\hline 15 & 1446 & 24.9 & 0.00001 & 1450 \\
\hline
\end{tabular}

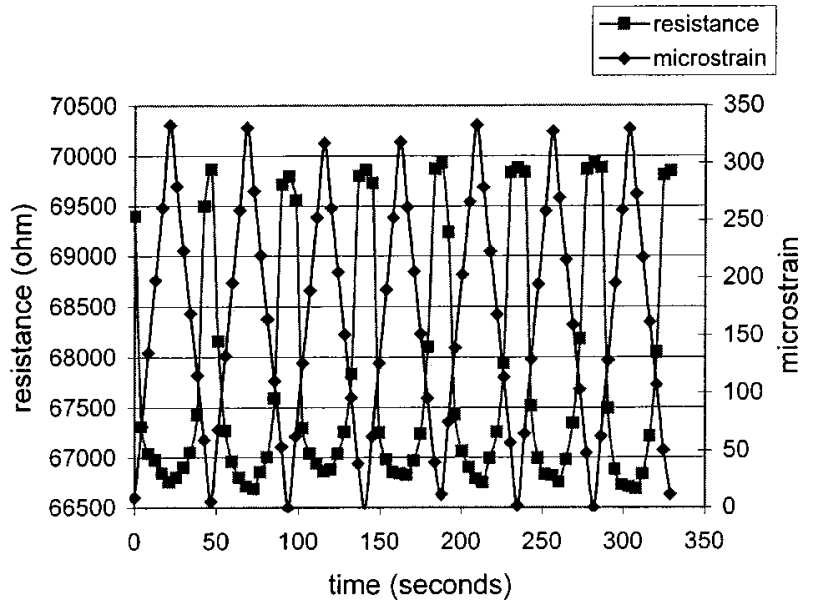

Figure 6. Piezoresistive response of a $10 \mu \mathrm{m}$ thick ITO strain sensor at $1528^{\circ} \mathrm{C}$. The strain sensor was subjected to a postdeposition heat-treatment in nitrogen and had a gage factor of 131 and a drift rate of $0.00001 \% / \mathrm{h}$. Note the excellent stability of the signal as evidenced by the small slope of the piezoresistive response.

served in Fig. 11, the average ITO particle size was considerably smaller and the ITO particles had a more angular and faceted morphology. In the case of the nitrogen-sputtered ITO films, it appears that nitrogen was metastably retained in the individual ITO grains during sputtering and diffused out of the bulk grains at elevated temperatures, eventually becoming trapped at grain boundaries and triple junctions. Under these conditions, sintering and densification of the ITO particles containing these nitrogen-rich grain boundaries was further retarded and a contiguous network of nanosized ITO particles was established. In either case, the controlled microstrucutres developed in these sensors were achieved by controlling the partial pressure of nitrogen in the interconnected porosity during processing, such that a balance between the rate of decomposition and the sintering rate was maintained so that the desired microstructure would persist for prolonged periods at

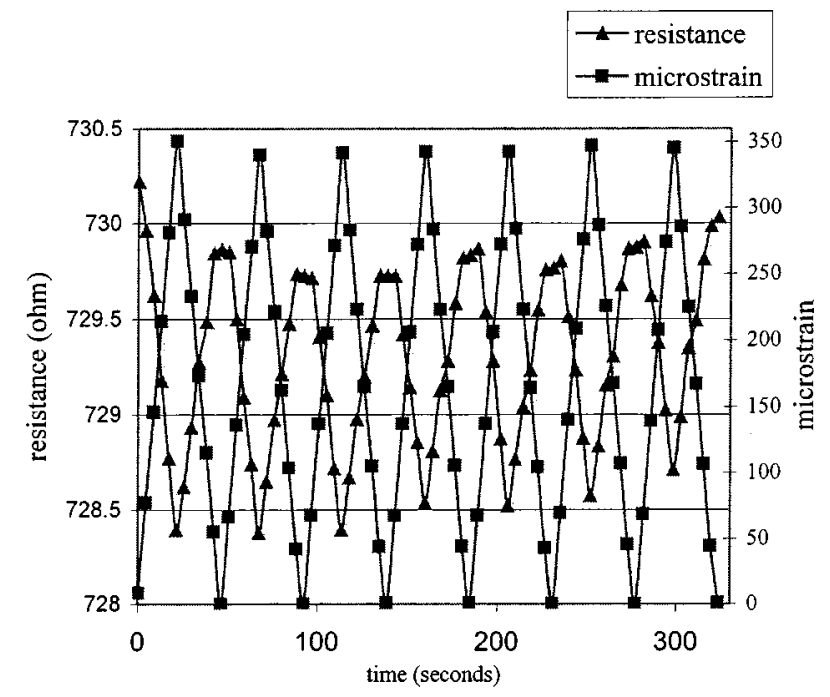

Figure 7. Piezoresistive response of a $15 \mu \mathrm{m}$ thick ITO strain sensor at $1446^{\circ} \mathrm{C}$. The strain sensor was subjected to a postdeposition heat-treatment in nitrogen and had a gage factor of 24.9 and a drift rate of $0.0001 \% / \mathrm{h}$. Note the considerably smaller baseline resistance shown here relative to the baseline resistance of the $10 \mu \mathrm{m}$ strain sensor shown in Fig. 6. Also note the excellent stability of the signal as evidenced by the small slope associated with the piezoresistive response. 

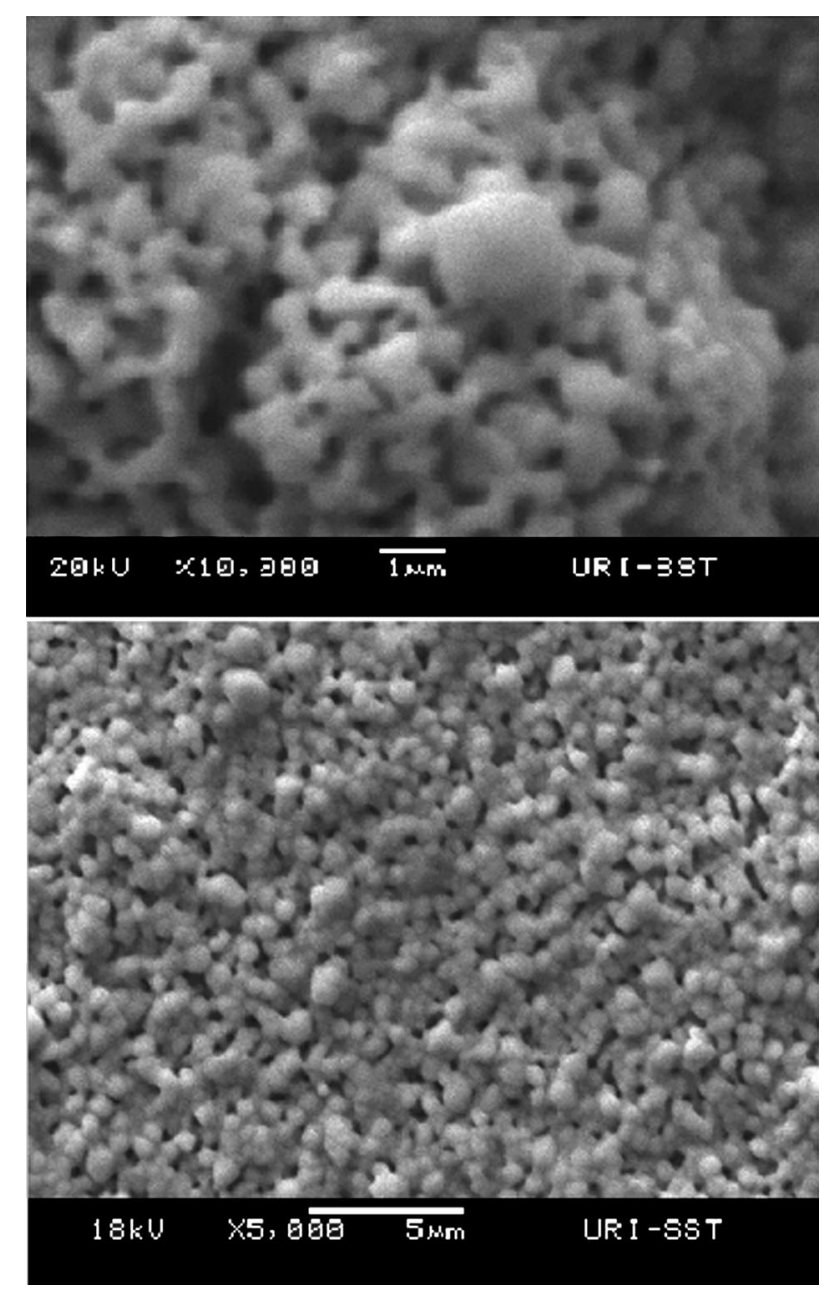

Figure 8. SEM micrographs of a $10 \mu \mathrm{m}$ thick ITO strain element after postdeposition heat-treatment in nitrogen and testing at $1528^{\circ} \mathrm{C}$. The micrographs show a partially sintered microstructure with extensive neck formation. Note the size and uniformity of the ITO particles and the associated porosity.

elevated temperatures. Since the decomposition of ITO alloys in pure nitrogen can occur at temperatures as low as $1100^{\circ} \mathrm{C},{ }^{20,21}$ the decomposition kinetics at higher temperatures can be controlled to a large extent by the nitrogen partial pressure maintained in the internal porosity.

Static strain testing further confirmed that sensors prepared with microstructures containing isolated nanporoes had improved stability and piezoresistive responses compared to ITO strain gages with a typical densified microstructure. The piezoresistive response of a ceramic strain gage prepared with only $6 \mu \mathrm{m}$ of a nitrogen-sputtered ITO film (Fig. 12) demonstrates the critical role that nitrogen plays in producing these stable nanoporous microstructures. This ITO thin-film sensor was prepared in a nitrogen-rich atmosphere and survived tens of hours of strain testing at $1553^{\circ} \mathrm{C}$ with a gage factor of 11.4 and a drift rate of $0.0001 \% / \mathrm{h}$. These results were significantly better than those obtained from thicker ceramic strain gages prepared in argon/oxygen ambients. For example, the piezoresistive response of an $8 \mu \mathrm{m}$ thick ITO sensor at $1441^{\circ} \mathrm{C}$, was reasonably good but became unstable at temperatures beyond $1481^{\circ} \mathrm{C}$. Thin nitrogen-sputtered films, however, were stable at temperatures of $1562^{\circ} \mathrm{C}$ and exhibited a reasonably large piezoresistive response and low drift rate $(0.0001 \% / \mathrm{h})$ at this temperature. When the thin nitrogen-sputtered films were compared to thick ITO sensors, the same excellent electrical stability was observed as indicated by the very low drift rates. Both types of nanoporous ITO films proved to

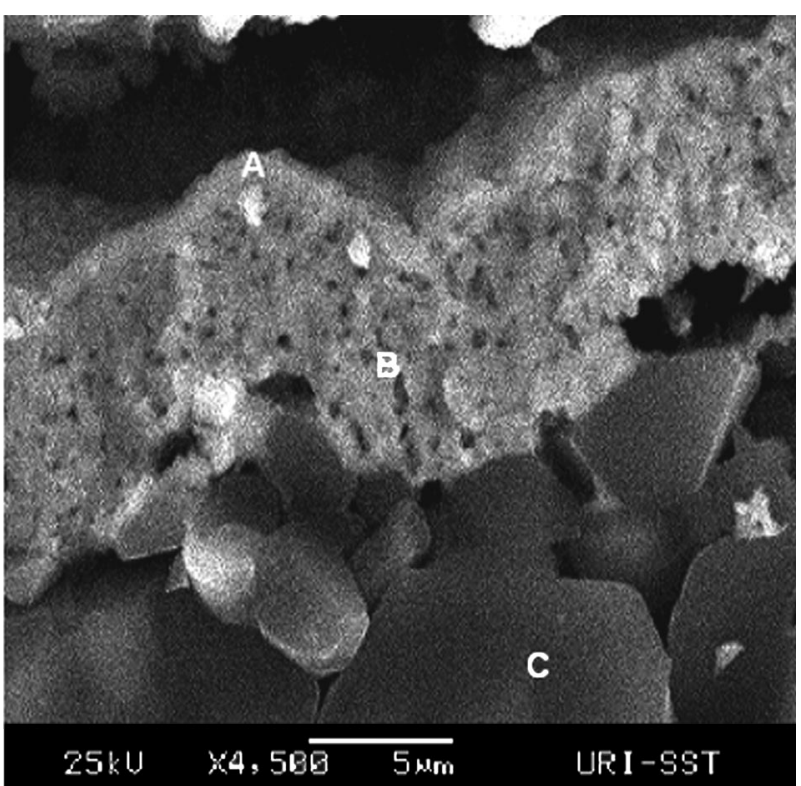

Figure 9. SEM micrograph of a fracture surface of a $10 \mu \mathrm{m}$ thick ITO strain element after postdeposition heat-treatment in nitrogen and $1500^{\circ} \mathrm{C}$ exposure. (A) A densified surface layer, (B) a partially sintered ceramic microstructure with controlled nanoporosity, and (C) a polycrystalline aluminum oxide substrate are clearly shown in the fractograph.

be effective oxygen diffusion barriers and slowed the migration of oxygen into the bulk film. This increased the stability of the ITO films, since the diffusion of oxygen through the nonstoichiometric indium-tin-oxide can lead to compensation of the doubly charged oxygen vacancies that are responsible for conduction in these materials. Since the higher density surface layers of the thicker ITO films make oxygen diffusion more difficult, the conductivity of the active sensor elements was much less affected by compensation and the electrical stability was significantly improved. ${ }^{13}$

\section{Conclusions}

ITO thin-film strain gages prepared with controlled nanoporosity were demonstrated at temperatures approaching $1600^{\circ} \mathrm{C}$. Hightemperature static strain tests indicated that the piezoresistive response and electrical stability of these ceramic strain sensors de-

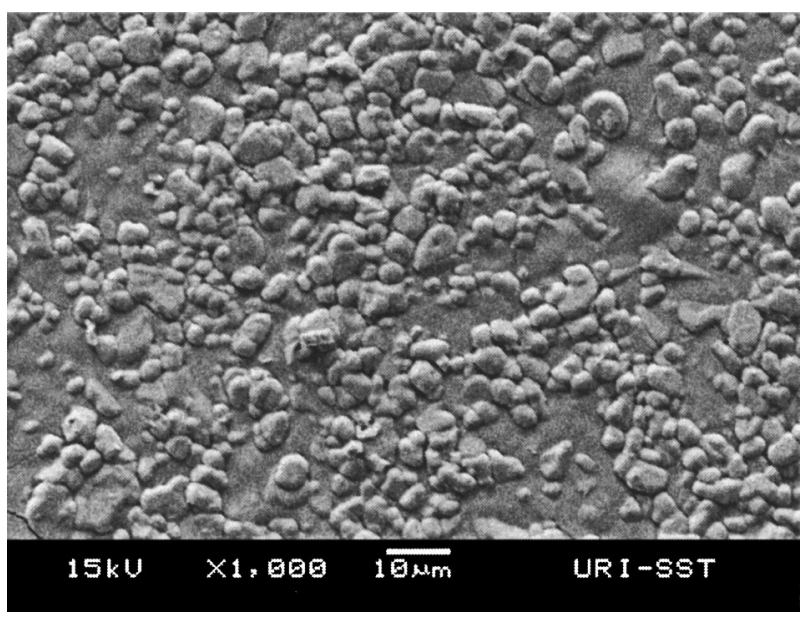

Figure 10. SEM micrograph of an as-deposited and annealed ITO strain sensor $(10 \mu \mathrm{m}$ thick). The micrograph shows that a relatively dense surface layer had developed in the ceramic after the postdeposition heat-treatment at $800^{\circ} \mathrm{C}$ in nitrogen. 


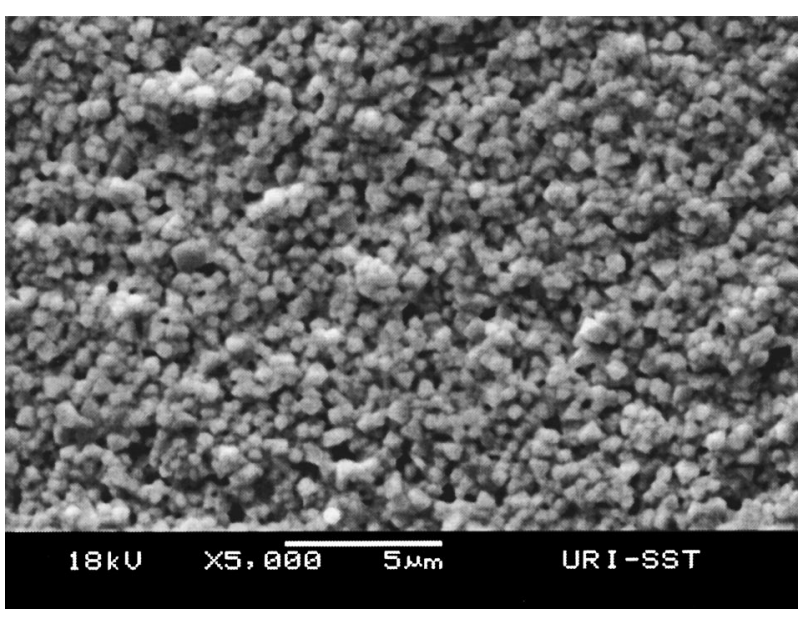

Figure 11. SEM micrograph of a $6 \mu \mathrm{m}$ ITO strain element that was prepared by sputtering in a nitrogen-rich atmosphere, heat-treated in nitrogen and tested at $1550^{\circ} \mathrm{C}$. Here a partially sintered microstructure with extensive neck formation similar to the sensor shown in Fig. 8 was observed, however, the morphology and size of the ITO particles are noticeably different.

pended on the thickness of ITO films comprising the active strain elements. When thick ITO gages were heat-treated in nitrogen am-

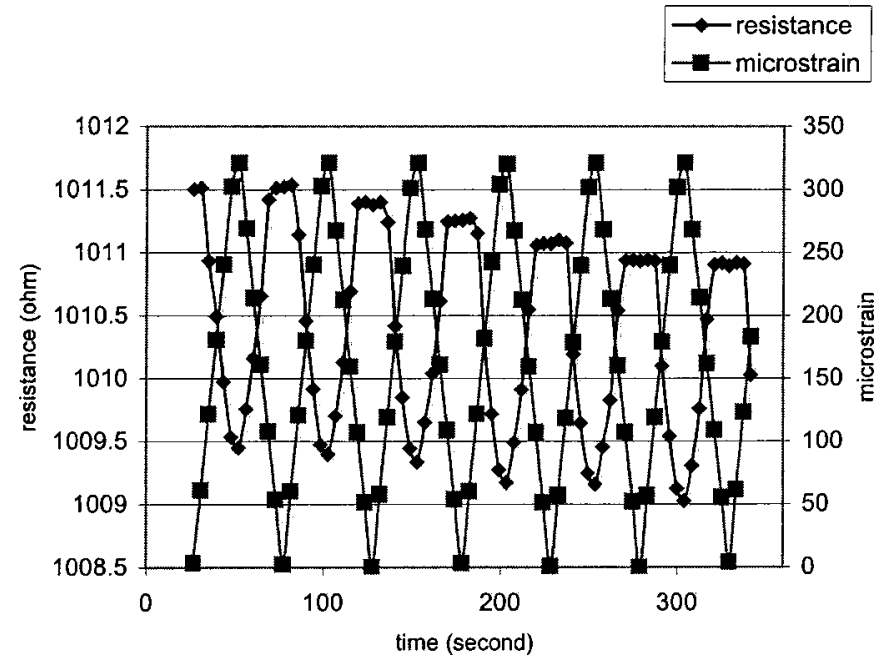

Figure 12. Piezoresistive response of a $6 \mu \mathrm{m}$ thick ITO strain sensor at $1553^{\circ} \mathrm{C}$. The strain sensor was sputtered in a nitrogen-rich environment and subjected to a postdeposition heat-treatment in nitrogen. It had a gage factor of 11.4 and a drift rate of $0.0001 \% / \mathrm{h}$. Note the excellent stability of the signal as evidenced by the relatively small slope of the piezoresistive response. The degradation of the waveform is due to warpage and deformation of the high purity alumina substrate and not the performance of the ITO sensor. bients, a partially sintered microstructure consisting of a contiguous network of submicrometer ITO particles with well-defined necks and isolated nanoporosity was established. It appeared that densification of the ITO particles was retarded during high-temperature exposure with nitrogen playing a key role in stabilizing the nanoporosity. Based on these findings, ITO strain sensors were also sputtered in various nitrogen partial pressures and annealed to produce sensors with similar characteristics. SEM confirmed that similar microstructures with controlled nanoporosity could be prepared by this method as well, but the average particle size was reduced by an order of magnitude. The electrical properties of relatively thin nitrogen-sputtered films were superior to those that were prepared from much thicker, annealed ITO films in terms of baseline resistivity, stability, and piezoresistive response. Static strain testing indicated that the ITO thin-film strain gages prepared with controlled nanoporosity survived repeated cyclic loading at temperatures as high as $1581^{\circ} \mathrm{C}$ for tens of hours. The microstructure of these ITO sensors consisted of a sintered or densified outer surface that protected the interior regions of the sensors from oxygen exposure. The detailed mechanism for stabilizing the ITO films to these high temperatures is not completely understood at this time and will require further investigation. However, there are considerable implications here for other types of ceramic gas sensors where microstructures with controlled nanoporosity are desired.

\section{Acknowledgments}

The authors thank NASA-Lewis Research Center, Cleveland, Ohio, for support of this work under NASA Aerospace Propulsion and Power Program NAG3-2526.

University of Rhode Island assisted in meeting the publication costs of this article.

\section{References}

1. C. O. Hulls, R. S. Bailey, and F. D. Leakey, NASA Report no. 174833 (1985).

2. W. H. Atkinson and R. R. Strange, NASA Contractor Report no. 182111 (1988).

3. J. F. Lei, NASA Report no. 185135 (1989).

4. J. F. Lei, NASA Report no. 185256 (1990).

5. C. Li, P. J. Hesketh, and G. J. Maclay, J. Vac. Sci. Technol. A, 12, 813 (1994).

6. J. F. Lei and H. A. Will, Sens. Actuators, A, 65, 187 (1998).

7. J. W. Pitts and D. G. Moore, National Bureau of Standards Monograph 26 (1961)

8. G. R. Witt, Thin Solid Films, 22, 133 (1974).

9. M. M. Lemcoe, in Proceedings of Sensors Expo International Conference, 203C1-7 (1989).

10. P. Kayser, J. C. Goderoy, and L. Leca, Sens. Actuators, 37-38, 328 (1993)

11. J. W. De Wit, J. Solid State Chem., 13, 192 (1975).

12. O. J. Gregory, T. You, and M. J. Platek, in Proceedings of 49th International Instrumentation, Systems and Controls Symposium, Orlando, FL (2003).

13. N. Nadaud, M. Nanot, and P. Boch, J. Am. Ceram. Soc., 77, 843 (1994).

14. O. J. Gregory, A. B. Slot, P. S. Amons, and E. E. Crisman, Surf. Coat. Technol., 88, 78 (1996).

15. O. J. Gregory, J. D. Cooke, and J. M. Bienkiewicz, in Proceedings of NATOAGARD Advanced Non-Intrusive Instrumentation for Propulsion Engines, Belgium (1997).

16. O. J. Gregory, NASA Annual Technical Report-Aerospace Propulsion and Power Program NRA-01-GRC-02 (2001-2002).

17. O. J. Gregory and Q. Luo, Sens. Actuators, A, 88, 234 (2001)

18. O. J. Gregory, Q. Luo, J. M. Bienkiewicz, B. W. Erwin, and E. E. Crisman, Thin Solid Films, 405, 263 (2002)

19. A. Garcia-Alonso, J. Garcia, E. Castono, I. Obieta, and F. J. Gracia, Sens. Actuators, A, 37, 784 (1993).

20. O. J. Gregory, Q. Luo, and E. E. Crisman, Thin Solid Films, 406, 286 (2002).

21. O. J. Gregory, and Q. Luo, in Proceedings of 19th Annual Digital Avionics Systems Conference, Philadelphia, PA (2000).

22. B. C. Kim, J. H. Lee, J. J. Kim, and T. Ikegami, Mater. Lett., 52, 114 (2002). 